\title{
Determination of Total Nitrogen in Cyanamide and Nitrate Mixtures-Davisson-Parsons Method ${ }^{1,2}$
}

\author{
By Kenneth D. Jacob and Walter J. Geldard
}

Fixed Nitroghn Research Laboratory, Department of Agriculture, Washington, D. C.

$I^{N}$ CONNECTION with an investigation on commercial calcium cyanamide (hereafter referred to as cyanamide), it became necessary to determine the total nitrogen in mixtures of cyanamide and nitrates. Several methods for the determination of total nitrogen, including nitrate nitrogen, in fertilizer mixtures have been adopted as "Official" by the Association of Official Agricultural Chemists. It is, however, well known that these methods do not give accurate results in the presence of much moisture. Mixtures of cyanamide and calcium nitrate usually contain considerable moisture, and in preliminary experiments we found that consistent results for total nitrogen could not be obtained by any of the official methods. A method for the determination of total nitrogen, including nitrate nitrogen, perfected by Davisson and Parsons ${ }^{3}$ for the analysis of soil and biological extracts, seemed to offer possibilities in this connection. In making a study of the applicability of this method to mixtures such as here considered, two official methods were also studied in comparison. These were the Gunning-Forster method, as used by the Nitrogen Laboratory of the Bureau of Chemistry, and the Gunning method modified to include the nitrogen of nitrates, and were selected as probably being the most reliable of the official methods for the determination of total nitrogen in cyanamide-nitrate mixtures.

\section{OUtline of Methods}

To avoid any confusion that might arise from referring to the various methods by name only, they are briefly described as follows:

The Gunning-Forster Method-To the weighed sample add 35 cc. of concentrated sulfuric acid (sp. gr. 1.84) containing $33.33 \mathrm{~g}$. salicylic acid per liter. Mix thoroughly and let stand over night. Add $5 \mathrm{~g}$. sodium thiosulfate, let stand for $4 \mathrm{hrs}$., and then digest for about $10 \mathrm{~min}$., beginning with a low flame and increasing to vigorous boiling as foaming subsides. Cool, add $10 \mathrm{~g}$. potassium sulfate, and boil steadily for at least $3 \mathrm{hrs}$. Cool, dilute, and distil in the usual way.

This method is known to give accurate results when the sample is finely powdered and dry. It is especially important that the sample be dry, for as little as 4 per cent of moisture will cause low results.

The Gunning Method, Modified to Include the Nitrogen of Nitrates ${ }^{4}$-This method is practically the same as the Gunning-Forster, with the exception that the sample is left in contact with the sulfuric-salicylic acid mixture, with frequent shaking, for only $30 \mathrm{~min}$. The sodium thiosulfate is then added and allowed to stand about $10 \mathrm{~min}$. before proceeding with the digestion.

It is open to the same objection as the Gunning-Forster

1 Received August 28, 1922.

2. Published by permission of the Department of Agriculture.

- This Journal, 11 (1919), 308

" "Methods of Analysis, A. O. A. C.," 1919, p. 8 method. The effect of moisture in samples has already been pointed out by several investigators ${ }^{3,5}$ and our results further confirm their conclusions.

The Davisson-Parsons M"THOD-The sample is placed in an 800-cc. Kjeldahl flask, 100 to $200 \mathrm{cc}$. distilled water added with sufficient 50 per cent sodium hydroxide to make the solution tenth normal. Sufficient Devarda's alloy $(\mathrm{Cu}-50, \mathrm{Al}-45, \mathrm{Zn}-5)$ to reduce all the nitrate nitrogen is then added. (One gram of alloy will reduce about 25 mg. nitrate nitrogen.) The flask is then connected to a Davisson-Parsons absorption tube containing $35 \mathrm{cc}$. of sulfuric acid (4:1), and reduction of the nitrate nitrogen to ammonia carried out, after which the acid in the absorption tube is allowed to suck back into the flask, and the tube thoroughly washed with distilled water. The solution is then evaporated to charring, 5 to $7 \mathrm{~g}$. potassium sulfate are added, and the digestion continued for about $1 \mathrm{hr}$. after the melt has become clear. The melt is then cooled, diluted, and distilled.

Since the determinations by this method were carried out exactly as recommended by Davisson and Parsons, the reader is referred to the original article for the exact details of procedure. The most important feature of this method is that the analysis is carried out in aqueous solution, and it is therefore immaterial whether the sample is solid or in solution. This eliminates the necessity of having the sample for analysis dry as in the case of the official methods.

A number of investigations ${ }^{6}$ on the use of Devarda's alloy for the determination of total nitrogen in mixtures of nitric and organic nitrogen have been carried out within the past few years. After comparison with the other methods, the various investigators are almost unanimous in the opinion that more uniform and reliable results can be obtained under a wider variety of conditions by the use of Devarda's alloy than with any of the other proposed methods. The majority of the workers used either the Davisson-Parsons procedure directly or a slight modification of it.

Comparison of the Davisson-Parsons Method with Official Gunning Mithod for Cyanamide Nitrogen Alone

Before making comparative tests of the foregoing methods for total nitrogen, it was necessary to determine the accuracy of the Davisson-Parsons method on extracts of cyanamide. As to its use for nitrate nitrogen alone, the results of other investigators ${ }^{7}$ are sufficient to indicate its accuracy.

A cyanamide extract was prepared by shaking a sample with water for $3 \mathrm{hrs}$., filtering, and making up to a definite volume. Aliquots of $50 \mathrm{cc}$. of this solution were analyzed

s Peck, This Journal, 3 (1911), 817.

- Pilz, Z. landw. Versuchw., 22 (1919), 180; Platou, Chimie et industrie, 3 (1920), 310; Flycht, Caliche, 1 (1919), 210; Baldi, Giorn. chim. ind applicata, 2 (1920), 376; MeLachlan, Pharm. J., 106 (1921), 477; Strowd, Soil Sci., $10(1920), 333$.

7 Mitscherlich and Herz, Landw. Jdhrb., 88 (1909), 279; Davisson and Parsons, see Note 3; Butt, ThIS JourNAI, 12 (1920), 352. 
by the official Gunning ${ }^{8}$ and Davisson-Parsons methods. The Gunning method (using potassium and copper sulfates) is recommended generally for total nitrogen in cyanamide and other fertilizer materials in the absence of nitrates.

The results of these analyses are given in the following table. All results given in this paper have been corrected for the nitrogen blank on the reagents alone.

TABIE I-COMPARISON OF THE OFFICIAI, GUNNING AND DAVISSON-PARSONS Methods on the Determination of Cyanamide Nitrogen Alone

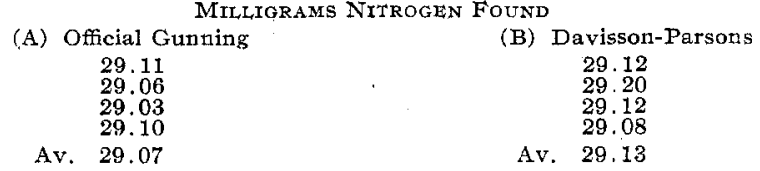

These results indicate that the Davisson-Parsons method accurately determines the total nitrogen of cyanamide extracts. The total nitrogen value for a 50 -cc. aliquot obtained in $\mathrm{B}, 29.13 \mathrm{mg}$, was used in the following as a basis for the cyanamide nitrogen contents in solutions containing both cyanamide and nitrate nitrogen.

\section{Comparison of Methods on Mixtures Conjaining Both Cyanamide and Nitrate Nitrogen}

AQUmous SAMPLES-The source of the nitrate nitrogen used in preparing these extracts was an approximately $0.04 \mathrm{~N}$ solution of nitric acid, carefully prepared from C. P. nitric acid. A series of nine analyses by the Davisson-Parsons method gave the average value for a 50 -cc. aliquot of $28.57 \mathrm{mg}$. of nitrate nitrogen.

Using the two values as given above for cyanamide and nitrate nitrogen, a number of mixtures containing 50-cc. of each of the solutions were prepared and analyzed by the three methods previously outlined. The composition of the mixtures was as follows:

$$
\begin{aligned}
& \text { 50 cc. cyanamide extract......... } 29.13 \text { nitrogen } \\
& 50 \mathrm{cc} \text {. nitric acid solution.......... } 28.57 \\
& \text { TOTAL ........... } \overline{57.70}
\end{aligned}
$$

\begin{tabular}{|c|c|c|}
\hline $\begin{array}{c}\text { Davisson-Parsons } \\
\text { Method }\end{array}$ & $\begin{array}{c}\text { MILIIGRAMS NITROGEN FoUnd } \\
\text { Gunning-Forster } \\
\text { Method }^{1}\end{array}$ & $\begin{array}{l}\text { Modified Gunning } \\
\text { Method }{ }^{1}\end{array}$ \\
\hline $\begin{array}{r}57.89 \\
57.91\end{array}$ & $\begin{array}{l}56.01 \\
56.91\end{array}$ & $\begin{array}{l}56.50 \\
56.66\end{array}$ \\
\hline 57.72 & $\begin{array}{c}56.61 \\
\ldots\end{array}$ & $\begin{array}{c}30.80 \\
\ldots\end{array}$ \\
\hline 57.64 & $\ldots$ & $\ldots$ \\
\hline 57.70 & $\cdots$ & $\cdots$ \\
\hline $\begin{array}{l}57.73 \\
57.70\end{array}$ & $\because$ & $\because$ \\
\hline 57.91 & $\ldots$ & $\ldots$ \\
\hline 57.87 & $\cdots$ & $\cdots$ \\
\hline $\begin{array}{l}56.80 \\
57.77\end{array}$ & $\because \cdots$ & $\cdots$ \\
\hline Av, 57.78 & 56.51 & 56.71 \\
\hline
\end{tabular}

The analytical results obtained were as follows:

${ }^{1}$ As previously stated, the Gunning-Forster and modified Gunning methods do not give reliable results in dilute solution; the 100 -cc. samples were therefore evaporated very carefully to a voltume of about $10 \mathrm{cc}$, befor because of possible loss of nitrogen.

These results indicate that the Davisson-Parsons method is applicable to solutions containing cyanamide and nitrate nitrogen. The results by this method agree closely and are as accurate as can usually be obtained in this type of determination. It should be noted that the effect of excess moisture is quite evident in the case of the official method, and for that reason only a limited number of determinations were made, as indicated in the above table.

8 "Methods of Analysis, A. O. A. C.," 1919, p. 7.
Solid Samples Low in Nitrate Nitrogen-In analyzing solid samples of nitrates and cyanamide, the agreement between the methods is somewhat closer. For this test, a sample of cyanamide containing a known amount of calcium nitrate was prepared and analyzed by both the GunningForster and Davisson-Parsons methods. The former method was selected rather than the modified Gunning because it is generally considered to give more accurate results. The composition of the sample was as follows:

$$
\begin{aligned}
& \text { Per cent } \\
& \text { Nitrate nitrogen........... } 1.10 \\
& \text { Cyanamide............. 15.53 } \\
& \text { Total........ } 16.63
\end{aligned}
$$

The analytical results are given in the following table:

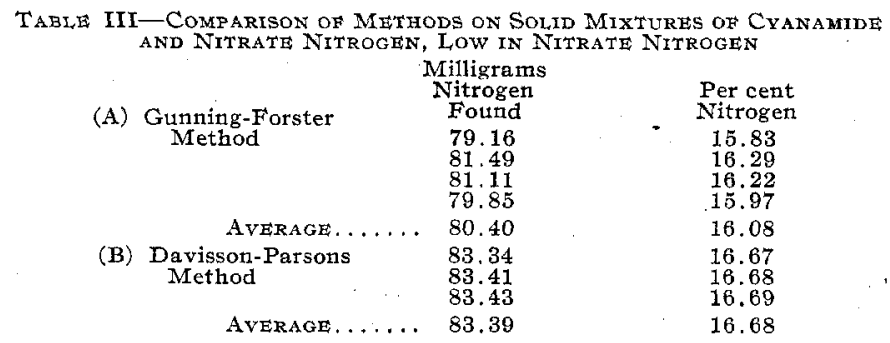

Solid Samples High in Nitrate Nitrogen-The mixture used above might be considered low in nitrate nitrogen, and therefore not a sufficient test of the reliability of the method. Another was prepared which contained more nearly equal parts of the two forms of nitrogen. Potassium nitrate

\begin{tabular}{|c|c|c|c|}
\hline (A) & -Fors & $\begin{array}{l}\text { Milligrams } \\
\text { Nitrogen } \\
\text { Foutrd }\end{array}$ & $\begin{array}{l}\text { Per cent } \\
\text { Nitrogen }\end{array}$ \\
\hline & $\begin{array}{l}\text { Method } \\
\text { Metsting }\end{array}$ & $\begin{array}{l}81.03 \\
79.37 \\
80.10 \\
79.47\end{array}$ & $\begin{array}{l}16.21 \\
15.87 \\
16.02 \\
15.89\end{array}$ \\
\hline & AVERAGE . . . . . & 79.99 & 16.00 \\
\hline (B) & $\begin{array}{l}\text { Davisson-Parsons } \\
\text { Method }\end{array}$ & $\begin{array}{l}83.02 \\
82.88 \\
83.02 \\
82.88\end{array}$ & $\begin{array}{l}16.60 \\
16.57 \\
16.60 \\
16.57\end{array}$ \\
\hline & AVERAGE . . . . . & 82.95 & 16.58 \\
\hline
\end{tabular}
(97.68 per cent) was mixed with cyanamide ( 20.42 per cent $N$ ) to produce a mixture of the following composition:

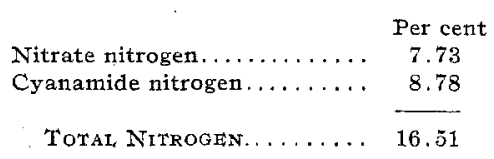

The results of analyzing this mixture are given below:

Table IV-Comparison of Methods on Solid Mixtures of Cyanamide and Nitrate Nitrogen, HIgh in Nitrate Nitrogen

Although neither of the two solid mixtures contained an appreciable quantity of free moisture, water was present combined as calcium hydroxide, since water is added to commercial cyanamide to hydrate the free lime. Moreover, cyanamide, when stored with access to the air, slowly absorbs additional moisture. Thus, it is readily seen that the cyanamide used in these mixtures might easily have contained a considerable quantity of combined water, which would be liberated on the addition of sulfuric acid, giving the low results noted above with the Gunning-Forster method.

In contrast to the unsatisfactory results given by other methods, those obtained with the Davisson-Parsons method are highly satisfactory and suggest the greater applicability of the method to fertilizers in general. Further work on this method with the view to its adoption as an official method for total nitrogen including nitrates therefore seems highly desirable. 